\title{
OPEN In vitro protective effects of Paeonia mascula subsp. hellenica callus extract on human keratinocytes
}

\author{
Sophia Letsiou ${ }^{1 \bowtie}$, Artemis Bakea ${ }^{1}$, Anna Holefors $^{2}$ \& Jadwiga Rembiesa ${ }^{2}$
}

Natural ingredients have been used to improve the state of health in humans. The genus Paeonia has been studied only limited yet it's reported to have many activities such as antioxidant and anti-inflammatory. To this context, here we focused on an endemic Paeonia species in Attica. This study aims to present the development of the Paeonia mascula subsp. hellenica callus extract and its pleiotropic bioactivity on human primary keratinocytes exploring its potential application as an active agent in skin-related products. This extract showed a high scavenging activity with high phenolic content and an interesting metabolic profile. At a molecular level, the study on the transcript accumulation of genes revealed that this extract exhibits in vitro skin-related protection properties by mediating mitochondrial energy, cell proliferation, immune and inflammatory response and positively regulates genes involved in epidermal and in stratum corneum function. Besides, the extract is proven not skin irritant on reconstructed human skin model. These findings indicate that the specific $P$. mascula subsp. hellenica extract possesses significant in vitro protection activity on human epidermis and provides new insights into its beneficial role in skin confirming that the advent of biotechnology contribution the past few decades.

From time immemorial since our days, plant-based products are used as effective ingredients for many purposes such as pharmacology, nutrition, or agrochemistry. Recently, the advent of biotechnology offers a plethora of methods to facilitate the use of plants in different products enhancing as well as preserving their efficacy as biotechnological in vitro methods aim to counteract the extension of rare natural species. Moreover, the use of natural extracts in skin care products is constantly increasing due to their protective properties ${ }^{1}$. To this context, here we present bioactivity assessments for the extract of Paeonia mascula subsp. hellenica (P. mascula subsp. hellenica) which considered to be a rare endogenus species.

In general, the genus Paeonia (Paeoniaceae) which has three sections (Moutan, Oneapia and Paeonia), has been studied only limited ${ }^{2}$. Specifically, from the 262 compounds that were identified in different parts of Paeonia only several anthocyanins were reported in Paeonia officinalis (P. officinalis) flowers and one (1,2,3,6-tetra-Ogalloyl-D-glucose) in its roots ${ }^{2}$. A large repertoire of bioactive substances were found in different Paeonia spp. that are responsible for their biological and pharmacological activities such as, in treatment for epilepsy, liver diseases and many other disorders ${ }^{3}$. Furthermore, it has been reported that Paeonia plants have many activities such as antioxidant, anti-inflammatory, anti-microbial, immune system modulation ${ }^{4-7}$. Besides the above, some Paeonia spp. such as P. lactiflora and P. suruticosa have been considered as a rich nutritional source of polyunsaturated oil and proteins ${ }^{8}$.

Among the 25 species of the section Paeonia that is distributed widely in Eurasia, two of them the species, Paeonia clusii and Paeonia parnassica, are endemic in Greece. The Greek Paeonia taxa, Paeonia mascula ssp. hellenica (synonym Paeonia officinalis var.mascula L.) has been studied only limited. Specifically, it has been reported that the roots of Greek Paeonia taxa has wound healing properties ${ }^{9}$. Another study reported that Paeonia mascula subsp. hellenica ( $P$. mascula subsp. hellenica) extract has strong skin whitening properties since its aerial parts was proven to provide a strong tyrosinase inhibition ${ }^{10}$.

Considering, the uniqueness, the rarity and the potential efficacy of $P$. mascula subsp. hellenica in skin, here we present the development of Paeonia mascula subsp. hellenica callus extract (PMCE), for the very first time, as

${ }^{1}$ Laboratory of Biochemistry, Research and Development Department, APIVITA S.A., Industrial Park of Markopoulo Mesogaias, Markopoulo Attiki, 19003 Athens, Greece. ${ }^{2}$ In Vitro Plant-Tech AB, Geijersg 4B, 21618 Limhamn, Sweden. ${ }^{凶}$ email: Letsiou-s@apivita.com 


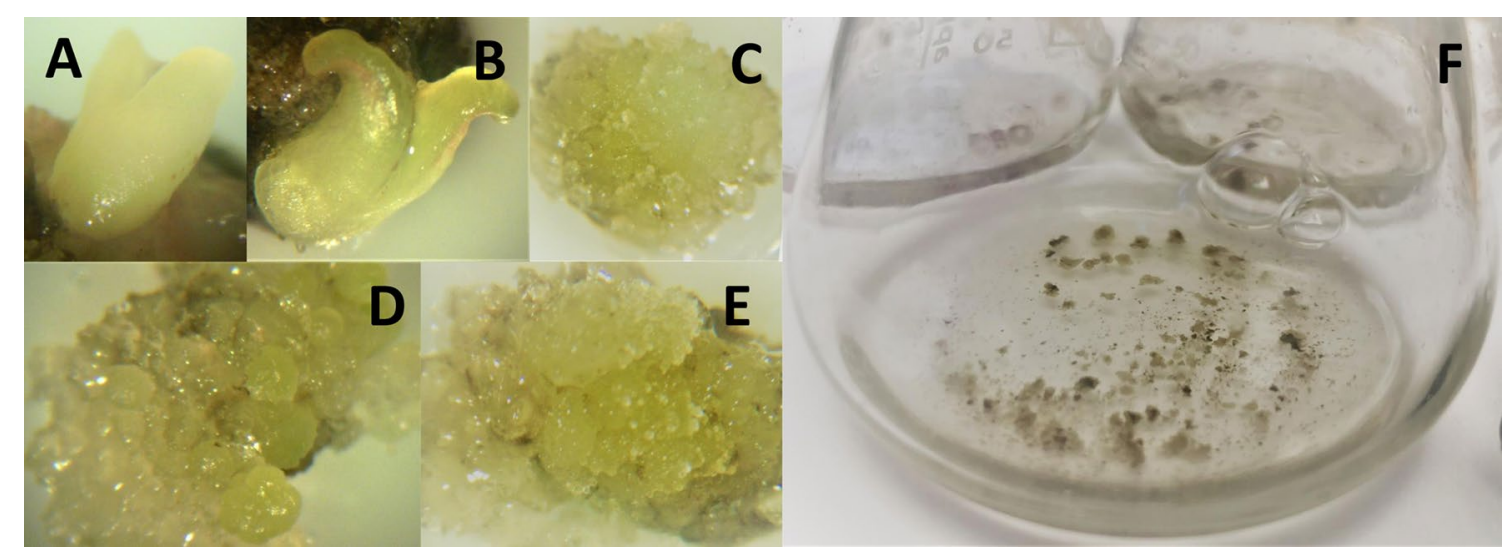

Figure 1. Initiation and growth of callus cell lines. Embryo formation (A, B), callus formation (C, D), callus with first stage globular embryos (E) growth of callus as small scale suspension cultures (F).

well as its in vitro biological effects in human primary keratinocytes with the aim to be used as an active ingredient in the development of skin-related products. To elucidate the molecular mechanism of PMCE bioactivity, we studied PMCE's antioxidant activity as well as the transcript accumulation for an array of selected genes involved in the function of the stratum corneum and the epidermal barrier.

\section{Results}

Initiation and growth of callus cell lines. From the dissected embryos and endosperm tissue we obtained formation of embryos and callus (Fig. 1). For callus induction and growth, we compared several different medium combinations for their ability to induce callus from dissected embryos. Callus cultures were successfully developed, where the best callus induction and callus growth was obtained on MS basal medium supplemented with PGR3 in combination with PGR1. The formed callus cultures were grown on both solid and liquid medium. Elicitation of bioactive substances were performed for suspension cultures using elicitor (E1). Treatment with E1 resulted in increased production of metabolites and was therefore selected for all further work.

Analysis of bioactive substances. The chemical analysis was based on total phenolic content (TPC), antioxidant (DPPH-EC50) and scavenging (E\%) activity. For the elicitated cells we obtained a mean TPC values of $106.2 \mathrm{mg} \mathrm{GA}$ equivalent/g dry extract. The antioxidant activity (EC50) obtained for elicitated cells was $0.011 \mathrm{mg} / \mathrm{mL}$, which corresponds to $\mathrm{mg}$ of extract required for a $50 \%$ decrease in absorbance of a $1 \mathrm{~mL}$ of DPPH solution. The scavenging activity (E\%) for the extract concentration $1 \mu \mathrm{g} / \mathrm{mL}$ was $11 \%$ as compared to standard ascorbic acid in the same concentration (14\%).

HPLC analysis. A general HPLC analysis (TIC profiling) was also performed. The chromatograms showed that the elicitated cells, marked green in Fig. 2, exhibited an interesting complex chemical profile with several dominant peaks. We found that the elicitated cells showed a more complex profile with additional peaks at 280 and $320 \mathrm{~nm}$ as compared to unelicitated cells. The TIC profile between different analysed samples showed reproducibility and we were able to detect major peaks for $\mathrm{RF}=9.28 ; \mathrm{RF}=19.6 ; \mathrm{RF}=28.03 ; \mathrm{RF}=34.87 ; \mathrm{RF}=42.72$ at wavelength $280 \mathrm{~nm}$ and for $\mathrm{RF}=18.88 ; \mathrm{RF}=22.33 ; \mathrm{RF}=23.22 ; \mathrm{RF}=24.70 ; \mathrm{RF}=30.38$ at wavelength $360 \mathrm{~nm}$.

Cell viability assessment. ATP has been used as a tool for determining the functional integrity of living cells. To this context, we determined intracellular levels of ATP in NHEK cells incubated with different concentrations of PMCE (Table 1). We observed that NHEK cells incubated with the lower concentrations of PMCE exhibited significantly higher ATP levels compared to control (Table 1).

Mitochodria functionality. Mitochondrial metabolism has traditionally been thought of as a source of cellular ROS production responsbible for many cellular processes. However, increased oxidative stress can hamper mitochondrial energy. Here, we report the protective role of PMCE in mitochondrial bioenergy against oxidative stress. We used hydrogen peroxidase as a stressor. Figure 3 depicts the protective role of PMCE in increased oxidative stress in NHEK cells. Specifically, the OCR levels are significantly decreased under oxidative stress $\left(\mathrm{H}_{2} \mathrm{O}_{2}\right)$ while the addition of PMCE under or no oxidative stress increase the OCR levels.

Reconstructed human skin model. To assess skin irritation potency conferred by PMCE or a formulation contains PMCE a reconstructed human epidermal model, EpiDerm EPI-200 (MatTek Corporation (Ashland, MA, USA) was used. According to Fig. 4, both the Paeonia mascula subsp. hellenica callus extract (Fig. 4A) and the formulation that contains it (Fig. 4B) were proven nonirritant for the human epidermis. 


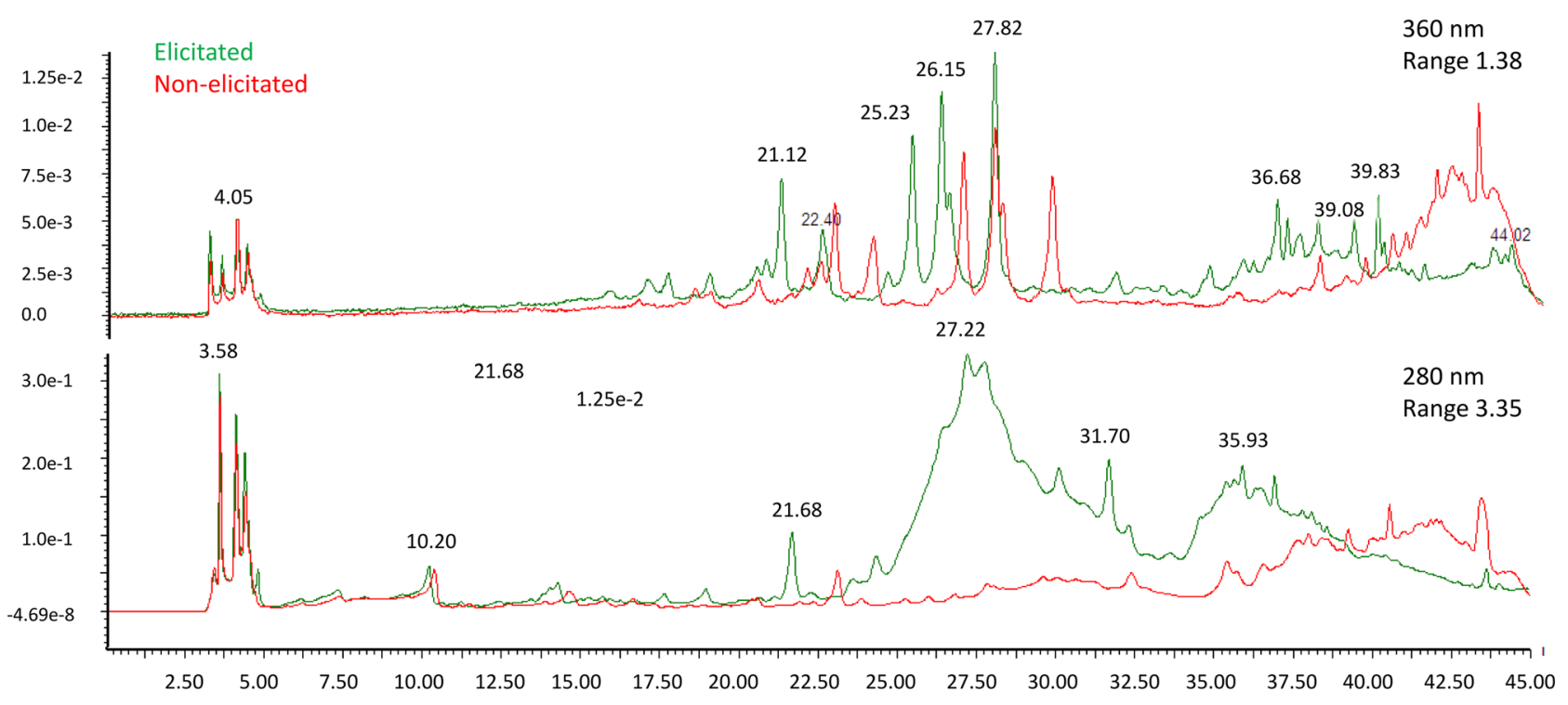

Figure 2. Represented chromatograms at 280 and $360 \mathrm{~nm}$ for elicitated (green) and unelicitated (red) cells.

\begin{tabular}{|l|r|l|}
\hline Cells treatment & \multicolumn{1}{|l|}{ ATP levels $(\mathrm{LUs})$} & Significance compared to control \\
\hline Untreated NHEK (control) & $6.37 \mathrm{E}+06 \pm 1.22 \mathrm{E}+05$ & NS \\
\hline$P M C E(1 \mu \mathrm{g} / \mathrm{mL})$ treated NHEK & $6.20 \mathrm{E}+06 \pm 1.41 \mathrm{E}+05$ & NS \\
\hline$P M C E(0.5 \mu \mathrm{g} / \mathrm{mL})$ treated NHEK & $5.97 \mathrm{E}+06 \pm 1.21 \mathrm{E}+05$ & NS \\
\hline$P M C E(0.1 \mu \mathrm{g} / \mathrm{ml})$ treated NHEK & $10.02 \mathrm{E}+06 \pm 1.22 \mathrm{E}+05$ & $<0.05$ \\
\hline$P M C E(0.05 \mu \mathrm{g} / \mathrm{mL})$ treated NHEK & $15.02 \mathrm{E}+06 \pm 1.22 \mathrm{E}+05$ & $<0.05$ \\
\hline
\end{tabular}

Table 1. Relative ATP levels (LUs) of NHEK cells after $48 \mathrm{~h}$ incubation with four concentrations of PMCE. Data are expressed as the mean \pm SEM for eight replicates.

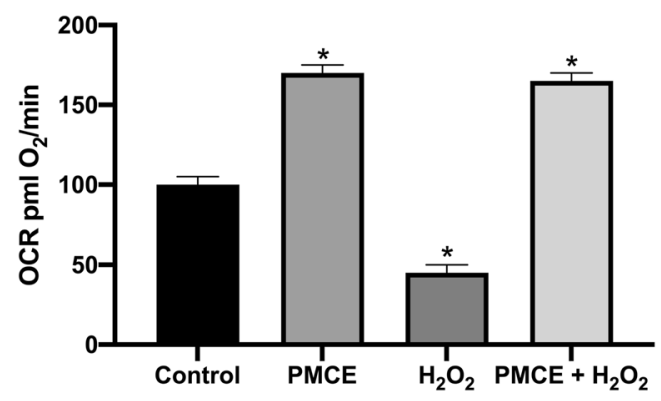

Figure 3. OCR levels expressed as mean \pm SEM for: control (untreated NHEK cells), NHEK cells treated with PMCE (PMCE), NHEK cells treated with $\mathrm{H}_{2} \mathrm{O}_{2}\left(\mathrm{H}_{2} \mathrm{O}_{2}\right)$ NHEK cells pre-treated with PMCE and after with $\mathrm{H}_{2} \mathrm{O}_{2}$ (PMCE $\left.+\mathrm{H}_{2} \mathrm{O}_{2}\right) .{ }^{*} \mathrm{p}<0.05$ significantly different from the control (ANOVA test).

Skin-related genes expression analysis. To have an insight into the effect and molecular mechanism of PMCE bioactivity in NHEK, we determined the expression of an array of genes involved in cell adhesion, desquamation, cell proliferation, lipids metabolism, and immune response. A detailed list of the target genes included in the present study and their respective relative expression levels is presented in Supplemental Table S1. Gene expression were measured by quantitative real time RT-PCR (RT-qPCR) using a developed platform containing the respective gene-specific primer pairs (Supplemental Table S2). Figure 5 shows the expression of genes that was significantly changed with the addition of $P$. mascula subsp. hellenica extract. As showed in Fig. 5, the expression of genes, inhibin subunit beta A (INHBA), Integrin alpha 1 (ITGA1), Occluding (OCLN), Paxillin (PXN), Caveolin 1 (CAV1), Tight junctions protein1 (TJP1), Cell Matrix adhesion regulator (CMAR), SCCE-stratum corneum chymotryptic enzyme (KLK7), FATPs-Fatty Acid Transport Proteins-3 (SLC27A3), ABCA-12 ATPbinding cassette A12 (ABCA12), b-glycocerebrosidase (GBA1) and $\beta$-defensins 4 (DEFB4) was up-regulated compared to control $(\mathrm{p}<0.05)$. In contrast, the expression of Corneodesmosin (CDSN), interleukin-1 alpha 

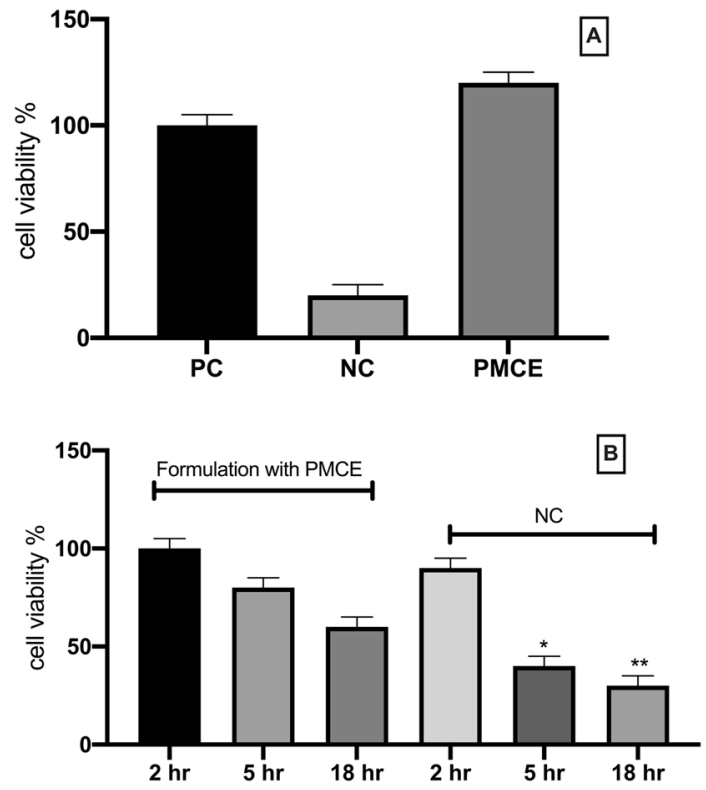

Figure 4. Cell viability levels expressed as mean \pm SEM based on reconstructed human skin model for: (A) reconstructed human skin model treated with PMCE, phosphate-buffered saline (DPBS) (positive control, PC) and 5\% Sodium Dodecyl Sulfate (SDS) (negative control, NC). (B) reconstructed human skin model treated with a cosmetic formulation with PMCE and $1 \%$ triton- 100 as negative control (NC). ${ }^{*},{ }^{* *} \mathrm{p}<0.05$ significantly different from the formulation point.

(IL1a) and interleukin-1 beta (IL1b), interleukin-6 (IL-6), interleukin-8 (IL-8), tumor necrosis factor alpha $(\mathrm{TNF}-\alpha)$ were down-regulated as compared to control $(\mathrm{p}<0.05)$.

\section{Discussion}

In this study, we have developed processes callus induction, growth and induction of bioactive substances for P. mascula subsp. hellenica. The formed callus showed a high scavenging activity, was high in total phenolic content and showed an interesting metabolic profile. For the formed callus we obtained a total phenolic content of $106.2 \mathrm{mg}$ GA equivalent/g dry extract and EC50 values of $0.011 \mathrm{mg} / \mathrm{mL}$. This is higher as compared to what has previously been recorded for Paeonia suffruticosa total phenolics in petals $(51.7 \mathrm{mg} \mathrm{GAE} / \mathrm{g})$ and stamens (77.3 mg GAE/g), whereas flowers and buds showed higher total phenolic values (113.8 and 191.8 mg GAE/g, respectively $)^{2}$. The DPPH radical scavenging activity was stronger for our developed callus culture as compared to all measured origins for P. suffruticosa, where the recorded EC50 values for petals, stamens, flowers and buds were $0.064,0.042,0.015$ and $0.034 \mathrm{mg} / \mathrm{mL}$, respectively. When comparing to callus cultures from other species, our developed $P$. mascula callus showed higher total phenolic content and stronger DPPH radical scavenging activity as compared with for example Zingiber officinale Rosc. (45.9 mg GAE/g and $0.727 \mathrm{mg} / \mathrm{mL}$ ), Trifolium pretense $(40.8 \mathrm{mg} \mathrm{GAE} / \mathrm{g}$ dry sample and $0.121 \mathrm{mg} / \mathrm{mL})$ and Asystasia gangetica $(27 \mathrm{mg} \mathrm{GAE} / \mathrm{g}$ extract and $0.0868 \mathrm{mg} / \mathrm{mL})^{11-13}$

In addition, we evaluated the in vitro biological effects of $P$. mascula subsp. hellenica extract in human primary keratinocytes, to address its potential applications in skin related research. Interestingly, our results demonstrated that PMCE increased the viability of human epidermal keratinocytes while enhancing mitochondrial activity under oxidative stress. The observed increased of ATP intracellular levels in keratinocytes clearly demonstrates that, at least in vitro, PMCE enhances cell viability, cell proliferation and energy metabolism of keratinocytes. According to previous reports, this increase is associated with higher levels of mitochondrial activity, energy metabolism and cell proliferation ${ }^{14,15}$ and is indicative of a lack of cytotoxicity ${ }^{14}$ In line with this, PMCE confers mitochondrial functionality under oxidative stress which is associated with the attenuated aging process as well as with the maintenance of significant cellular functions ${ }^{16,17}$.

To have broader spectrum of PMCE action in NHEK cells we assessed genes involved in different pathways related to epidermis-related cellular function. Under our experimental conditions several genes where found to be transcriptionally modulated by PMCE. To start with, we assessed the cell proliferation. The gene INHBA encodes a member of the TGF-beta (transforming growth factor-beta) superfamily of proteins involved in cell proliferation processes such as wound healing, inflammation ${ }^{18,19}$. In our study we observed that the gene expression of INHBA was up-regulated in NHEK cells treated with PMCE compared to control. This induction is in accordance with a previous reported study ${ }^{20}$ and shows that PMCE stimulates the proliferation of human keratinocytes confirming the previously mentioned increased ATP intracellular levels. Moreover, we explored the potential role of PMCE in inflammation investigating the proinflammatory cytokines IL1, IL6, IL8, TNF- $\alpha$. In particular, IL1 promotes local inflammation and coagulation ${ }^{21}$, IL6 stimulates the synthesis of fibrinogen that ultimately contribute to inflammatory acute phase $\mathrm{e}^{21}$ while $I L 8$ is a involved in many inflammation related processes such 

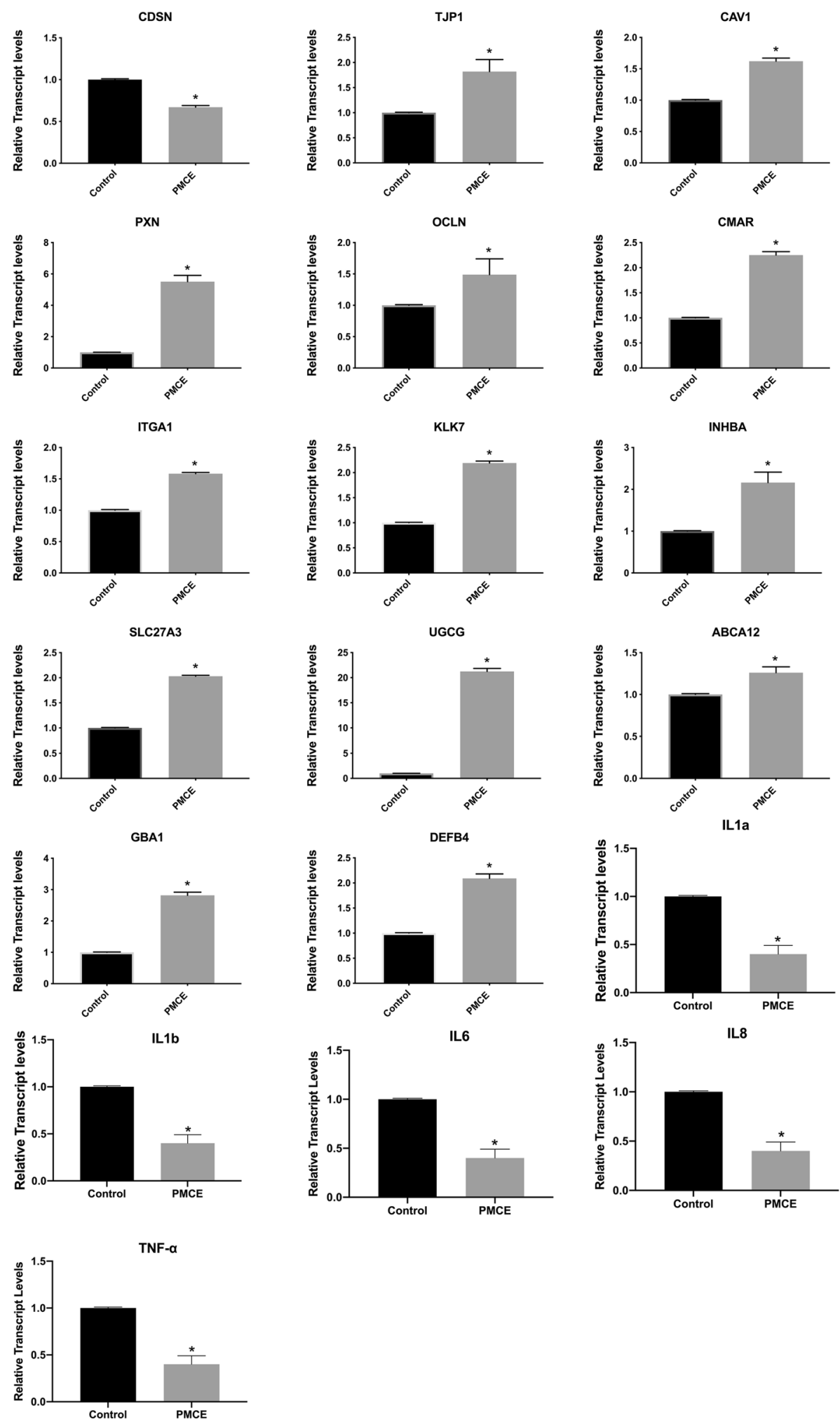

Figure 5. Relative gene expression of: CDSN, TJP1, CAV1, PXN, OCLN, CMAR, ITGA1, KLK7, INHBA, SLC27A3, UGCG, ABCA12, GBA1, DEFB4, IL1 $\alpha$, IL1 $\beta$, IL6,IL8,TNF- $\alpha$ expressed as a fold change \pm SEM compared to the control NHEK cells and using ACTB and GADPH as internal reference genes. The experimental conditions were control cells, cells treated with PMCE $(0.05 \mu \mathrm{g} / \mathrm{ml})(\mathrm{PMCE}) .{ }^{*} \mathrm{p}<0.05$ indicates groups significantly different from the control (ANOVA test). The data correspond to the mean \pm SEM of three independent experiments and six replicates each time. 
as chemotaxis of basophil and angiogenesis ${ }^{22}$ and TNF- $\alpha$ is an essential mediator in inflammation ${ }^{23}$. Here, we observed that the gene expression of IL1, IL6, IL8, TNF- $\alpha$ were downregulated in NHEK cells treated with PMCE compared to control. This downregulation is in agreement with previous reports ${ }^{24-26}$ emphasizing PMCE's role as an anti-inflammatory agent. On the other hand, we investigated genes that are involved in immune response in epidermis layer. Human $\beta$-defensin 2 (hBD2), encoded by the DEFB4 gene, is an inducible antimicrobial peptide with molecular mass of $4-6 \mathrm{kDa}$ acting as an endogenous antibiotic in the defense of host against Gram-positive and Gram-negative bacteria, fungi and the envelope of some viruses, and is involved in the innate immune response because its release is induced by pro-inflammatory cytokines, endogenous stimuli, infections or wounds ${ }^{27,28}$. Interestingly, in our study, we observed an induction of DEFB4 in NHEK cells treated with PMCE. The same induction has been observed before in human primary keratinocytes ${ }^{24-26,29}$, although this trend suggests a potential role of PMCE in antimicrobial process regulation yet it needs to be further elucidated.

Cell adhesion is not only essential for all multicellular organisms to interact and coordinate within cell populations but also critical for unicellular organisms to exchange signals with their microenvironment. Here, we assessed the gene expression of ITGA1, OCLN, PXN, CAV1, TJP1, CMAR that are related to cell adhesion and epidermal barrier function. Adhesion receptors include integrins, the immunoglobulin superfamily, cadherins, cellular adhesion molecules (CAMs), and homing receptors. Among all the cell adhesion receptors, integrins are important for "maintaining the integrity of the cytoskeletal-ECM linkage ${ }^{30}$. ITGA1 Integrin alpha-1/beta-1 is a receptor for laminin and collagen ${ }^{31}$. We observed that the gene expression of ITGA1 was up-regulated in NHEK treated with PMCE as compared to control, which potentially indicate an enhancement of integrins activity. Moreover, we evaluated the genes that encode the epithelial TJ proteins (occludin, and TJP1). OCLN encodes occludin, one of the epidermal tight junctions, since the expression of OCLN restores the function of tight junctions in disturbed epithelial cells ${ }^{32}$ it indicates that the increase of OCLN expression will restore skin barrier function according to previous report ${ }^{33}$. TJP1 is found in cytoplasmic plaques of tight junctions and is thought that TJP1 is involved in creating the proper organization of proteins within the tight junctional plaque ${ }^{34}$. Previous study showed that improving the expressions of tight junction proteins such as occluding or TJP1 has an effect on repairing epithelial barrier either in vitro and in vivo ${ }^{35}$. In our study, both the expression of OCLN and TJP1 were upregulated in NHEK treated with PMCE showing the positive function of cytoplasmic plaques of tight junctions due to the addition of the extract. The paxillin $(P X N)$ gene is a $68-\mathrm{kD}$ a tyrosine-containing protein that acts as an adaptor protein that integrates integrin, adhesion molecule, and growth factor signals ${ }^{36}$. PXN interacts with integrins during matrix organization and tissue remodeling by destabilizing focal adhesions, such as the linkage between $P X N$ and actin filaments ${ }^{37}$. Caveolae are sphingolipid- and cholesterol-rich plasma membrane microdomains found in diverse cell types, most prominently in adipocytes, endothelial cells, fibroblasts, and muscle cells ${ }^{38}$. Caveolae-1 has a critical role in lipids uptake of these cells ${ }^{39}$. It has been reported that induction of $C A V-1$ is associated with keratinocytes differentiation ${ }^{38}$. In our study, we observed that the gene expression of $C A V-1$ and $P X N$ were up-regulated in NHEK treated with PMCE potentially indicating keratinocytes differentiation. The gene CMAR encodes a mitochondrial metalloprotease protein that is a member of the AAA family. $C M A R$ has been suggested to be a signal transduction molecule influencing cell adhesion to collagen. Here, the expression of CMAR was up-regulated in NHEK treated with PMCE compared to control. However, further work is needed to fully understand this interaction.

Another process that is essential in skin barrier function is desquamation process. In the desquamation process, kallikrein (KLK)-related peptidases such as KLK5 and KLK7 degrade CDSN and induce cleavage of corneodesmosomes, resulting in detachment of corneocytes ${ }^{40}$. In the SC, the corneocytes are tightly bound together via corneodesmosomes, the end product of epidermal desmosomes modified by the incorporation of corneodesmosin (CDSN). It has been reported that down-regulated levels of CDSN are associated with barrierrelated defects ${ }^{41}$. In our study we observed a down-regulation in expression levels of CDSN in NHEK treated with PMCE compared to control. Nevertheless, further work is needed to fully understand this interaction. On the other hand, KLK7 has a primary role in the physical and biochemical barrier functions of the stratum corneum ${ }^{42}$. Recently it has been reported that reduction of $K L K 7$ is associated with unhealthy skin states ${ }^{43}$ interestingly, in our study we observed that the expression of KLK7 was up-regulated in NHEK treated with PMCE indicating a protective activity of stratum corneum functions.

Furthermore, we investigated the lipids replenish system. The gene SLC27A3 belongs to the SLC27 gene family that is comprised of six members, SLC27A1-6, which encode fatty acid transporters proteins (FATPS) ${ }^{44}$. The FATPs family play a vital role in formation of the epidermal permeability barrier ${ }^{45}$. It has been reported that reduced levels of SLC27A3 are connected with skin dysfunction and skin dehydration ${ }^{46}$. In our study we observed that the expression of SLC27A3 was up-regulated in NHEK treated with PMCE, indicating an enhancement of epidermal barrier preventing dehydration. The gene UGCG encodes the enzyme which catalyze the first glycosylation step in the biosynthesis of glycosphingolipids ${ }^{47}$. Previous study showed that UGCG deficiency in skin leads to epidermal barrier dysfunction. Epidermal barrier function has mainly been attributed to the SC, composed of lipid-embedded corneocytes and a lipid-enriched extracellular matrix ${ }^{48}$, as well as to TJ proteins preventing paracellular diffusion and transport ${ }^{49}$. Disturbance of one of those factors may lead to severe dermatoses such as ichthyoses, atopic dermatitis and psoriasis ${ }^{50-54}$. Here, we observed that the expression of UGCG was up-regulated in NHEK cells treated PMCE, which indicates that the extract might support optimum epidermal barrier function. The $A B C A 12$ encodes a transporter of lipids that delivers glucosylceramide to epidermal lamellar bodies in keratinocytes ${ }^{55}$. The increase of $A B C A 12$ expression is in accordance with previous report ${ }^{33}$ where it's stated that increase of $A B C A 12$ expression would restore the delivery of complex sphingolipids to the lamellar bodies of keratinocytes and accelerate maturation of the skin permeability barrier function. GBA1 is an acid $\beta$-glucosidase normally located in lysosomes, converts (glucosyl) ceramides into ceramides, which is crucial to generate an optimal barrier function of the outermost skin layer, the stratum corneum $(\mathrm{SC})^{56,57}$. Previous reports have showed 
that reduction on GBA1 expression may lead to an impaired barrier function that has been encountered in several inflammatory skin diseases ${ }^{58,59}$. Here, we observed that the expression of GBA1 was up-regulated in NHEK treated with PMCE indicating an enhancement of the optimal barrier function of the SC.

Additionally, the reconstituted human skin model was utilized to further confirm the protective properties of PMCE on human epidermis ${ }^{60,61}$. In our study, both the PMCE and its incorporation in a cosmetic formulation were proven non irritant for the epidermis which is an essential step during the development of new skin care related products.

To summarize, in the present study, we developed an effective callus extract independently of external factors (e.g. soil composition or climate, microorganisms or insects) preserving the uniqueness and the rarity of the plant species Paeonia mascula subsp. hellenica. We demonstrated that the P. mascula subsp. hellenica callus extract confers mitochondrial activity and modulates the expression levels of several genes involved in epidermis function. In line with that, we proved the efficacy of this extract on a human reconstructed skin model. These findings suggest that the P. mascula subsp. hellenica callus extract is a promising agent for the development of natural cosmetic products. Future studies are required to shed more light into elucidating the molecular mechanism(s) underlying the cytoprotective properties of $P$. mascula subsp. hellenica as well as its efficiency at clinical level.

\section{Methods}

Callus induction and growth of callus. During the spring 2018 plant material from P. mascula subsp. hellenica was collected and used to initiate the in vitro cultures. The material was surface sterilised using a 1:50 dilution of Clorox solution and thereafter rinsed using sterile water. Seeds were used to initiate in vitro callus cultures; these were grown on $\mathrm{MS}^{62}$ basal medium supplemented with BAP (benzylaminopurine, Duchefa Biochemie B.V, Haarlem, Netherlands) and gibberellic acid (GA3, Duchefa Biochemie B.V, Haarlem, Netherlands). The dissected embryos were used for induction and growth of callus cultures. For callus induction and growth MS basal medium supplemented with different combinations of PGR1-3 were compared. Callus was subcultured every third week on MS basal medium supplemented with PGR1 and 3. For elicitation Elicitor 1 was used.

Extraction of bioactive substances. Bioactive substances were extracted using a multistep extraction process: water, followed gradually increasing concentrations of ethanol, ranging from 50 to $80 \%$, to obtain extracts a broad range of active substances with different chemical and polar properties. Biomass:solvent ratios of 1:30-1:50 was used. Extraction was performed using ultrasonic water bath, $3 \times 10$ min cycles, followed by centrifugation, removal of supernatant and filtration.

Total phenolic content. Total phenolic content was measured using the Folin-Ciocalteu reagent (FCR assay), according to Chakrabothy and Ghorpade ${ }^{63}$ with the following modifications. A total of $20 \mu \mathrm{L}$ extract was mixed with $780 \mu \mathrm{L} \mathrm{H}_{2} \mathrm{Odd}$ and $50 \mu \mathrm{L}$ of Folin-Ciocalteu reagent (EMD Millipore, Burlington, MA, USA). After $7 \mathrm{~min}, 150 \mu \mathrm{L}$ of saturated $\mathrm{Na}_{2} \mathrm{CO}_{3}$ solution (VWR Chemicals, Radnor, PA, USA) was added. The samples were mixed and incubated at $30^{\circ} \mathrm{C}$ for $1 \mathrm{~h}$ in full darkness. Absorbance was thereafter measured using spectrophotometric measurements at $765 \mathrm{~nm}$ (GENESYS 20, Thermo Scientific, Waltham, MA, USA). Gallic acid (Cayman Chemical Company, Ann Arbor, MI, USA) was used as a standard and the calibration curve was linear in the range $0.03-1 \mathrm{mg} / \mathrm{mL}$. The results were presented as $\mathrm{mg}$ gallic acid equivalent (GAE)/g dry extract. Two biological replicates were analysed, where each sample was examined for three different extract dilutions, each of them in three technical replicates.

Scavenging capacity by DPPH assay. Radical scavenging activity of the crude extracts were determined using the 2,2-diphenyl-1-picrylhydrazyle (DPPH) assay as described by Brand-Williams et al. ${ }^{64}$, ${ }^{65}$ with the following modifications. The reaction was downscaled to $1 \mathrm{~mL}$ total volume. A total of $25 \mu \mathrm{L}$ extract was mixed with $975 \mu \mathrm{L}$ of a $24 \mu \mathrm{g} / \mathrm{mL}$ (w/v) DPPH solution in ethanol (SIGMA, Saint Louis, MO, USA; VWR Chemicals, Radnor, PA, USA) and incubated at room temperature for $30 \mathrm{~min}$ in full darkness. Ascorbic acid (Duchefa Biochemie, Haarlem, The Netherlands) was used as a standard and the calibration curve was linear in range $0.00003-0.004 \mathrm{mg} / \mathrm{mL}$. The absorbance was measured using spectrophotometric measurements at $515 \mathrm{~nm}$ (GENESYS 20, Thermo Scientific, Waltham, MA, USA). Two biological replicates were analysed, where each sample was analysed for six different extract concentrations. The measurement was performed using two technical replicates. The results were presented as EC50 value [mg dry extract/mL DPPH solution].

HPLC analysis. For HPLC analysis, the Waters Alliance 2790 HPLC Separations Module with 996 PDA Detector, with Column Hypersil GOLD instrument (RP, C18, dimensions $250 \times 4.6 \mathrm{~mm}$, particle size of $5 \mu \mathrm{m}$ ) (Thermo Scientific, Waltham, MA, USA) was used. A total of $10 \mu \mathrm{L}$ of a $10 \mathrm{mg} / \mathrm{mL}$ extract was injected and analysed. The mobile phase consisted of A: 1\% acetic acid (VWR International, Radnor, PA, USA) and B: methanol (VWR Chemicals, Radnor, PA, USA) with gradient (Table 2) and a flow of $1 \mathrm{~mL} / \mathrm{min}$.

Human skin cell culture. Primary Normal Human Epidermal Keratinocytes (NHEK) isolated from normal human adult skin were purchased from Lonza Clonetics (Lonza Walkersville, USA) ${ }^{17}$. Cells were cultured according to Lonza instructions. The cells were grown in a recommended media FGM-2 BulletKit that contained $2 \%$ serum. Cells were subcultured when reached $70-80 \%$ confluence. The cells were incubated for $48 \mathrm{~h}$ with PMCE in different concentrations $(0.05-1 \mu \mathrm{g} / \mathrm{ml})$. After the incubation, ATP determination and RNA isolation followed. 


\begin{tabular}{|l|l|l|}
\hline Time $(\mathbf{m i n})$ & \% mobile phase A & \% mobile phase B \\
\hline 0 & 95 & 5 \\
\hline 2 & 95 & 5 \\
\hline 10 & 75 & 25 \\
\hline 20 & 60 & 40 \\
\hline 30 & 50 & 50 \\
\hline 40 & 0 & 100 \\
\hline 45 & 95 & 5 \\
\hline
\end{tabular}

Table 2. Gradient for HPLC analysis. Mobile phase A 1\% acetic acid, Mobile phase B methanol.

Determination of ATP levels. The determination intracellular ATP was based on ViaLight HS BioAssay kit (Lonza) ${ }^{66,67}$. GloMax 20/20 single-tube luminometer (Promega) was used.

Mitochondria functionality. Oxygen consumption rate (OCR) in NHEK cells was measured in real-time using a Seahorse XFe24 Analyzer (Agilent, USA). Cells $\left(2 \times 10^{4}\right.$ cells/well) were seeded in the XF-24 plate and incubated for $48 \mathrm{~h}$ with the PMCE extract $(0.050 \mu \mathrm{g} / \mathrm{mL})$. After incubation, cells were exposed to $\mathrm{H}_{2} \mathrm{O}_{2}(0.5 \mathrm{mM})$ for $1 \mathrm{~h}$, according to previously conducted studies to determine the concentration of $\mathrm{H}_{2} \mathrm{O}_{2}$ as well as the exposure time ${ }^{66,68}$. The OCR levels in control (untreated NHEK cells), PMCE pre-treated NHEK cells and in cells stressed with $\mathrm{H}_{2} \mathrm{O}_{2}$ with and without pretreatment with the PMCE were measured. The readings were performed three times for each state with three min given for each reading and data were expressed as $\mathrm{pmol}$ of $\mathrm{O}_{2}$ consumed per minute.

Gene expression characterization by RT-qPCR. At first place, total RNA (tRNA) (500 ng) was isolated from all the samples using a Nucleospin RNA kit (Macherey-Nagel, Germany) and cDNA was prepared using the PrimeScript-RT reagent kit (Takara Bio, Japan) following the manufacturer's instructions. RT-qPCR was used to characterize the molecular changes associated with PMCE bioactivity in NHEK cells as described before $^{66-68}$. Briefly, quantitative RT-PCR reactions were performed using KAPA SYBR FAST qPCR Master Mix (Kapa Biosystems, Inc., Wilmington, Massachusetts, US), gene specific primers at a final concentration of $0.5 \mu \mathrm{M}$ each and $1 \mu \mathrm{L}$ of the cDNA as template. The RT-qPCR cycle was performed in a CFX connect TM Real Time System (Bio-Rad Laboratories, Hercules, California, USA) and the cycle used was: $95^{\circ} \mathrm{C}$ for $10 \mathrm{~min}$, followed by 40 cycles of $95^{\circ} \mathrm{C}$ for $15 \mathrm{~s}$ and $60^{\circ} \mathrm{C}$ for $1 \mathrm{~min}$. Supplementary Tables S1 and S2 provide a list of target genes as well as the respective gene-specific primer pairs respectively. The primer pairs were designed using Primer Express 1.5 software (Applied Biosystems, Darmstadt, Germany). The primer specificity and formation of primer-dimers was monitored by dissociation curve analysis and gel electrophoresis of the reaction products on a $4 \%(\mathrm{w} / \mathrm{v})$ TBE agarose gel. For the relative gene expression, comparative threshold cycle $(\mathrm{Ct})$ method was used $^{69}$ and normalization based on two reference genes Actin beta (ACTB) and Glyceraldehyde-3-phosphate dehydrogenase (GAPDH). The experimental conditions that were analyzed by RT-qPCR and presented here, were: untreated NHEK cells (control), NHEK cells treated with PMCE $(0.05 \mu \mathrm{g} / \mathrm{mL})(P M C E 0.05 \mu \mathrm{g} / \mathrm{mL})$. All RT-qPCR reactions were performed on three biological replicates following by eight technical repeats.

Reconstructed human skin model. To assess of any skin irritation potency conferred by PMCE a reconstructed human epidermal model, EpiDerm EPI-200 (MatTek Corporation Ashland, MA, USA) was used. The model consists of normal, human-derived epidermal keratinocytes, which have been cultured to form a multi-layered, highly differentiated model of the human epidermis. The tissue exhibits organised basal, spinous and granular layers, and a multi-layered stratum corneum containing intercellular lamellar lipid layers arranged in patterns analogous to those found in vivo ${ }^{61}$. Because it closely mimics the human epidermis, it has proven its scientific relevancy in studies where dermal exposure and toxicity is anticipated: skin corrosion testing of chemicals, skin irritation studies of cosmetic products and raw materials, phototoxicity, and skin penetration studies $s^{60,70}$. Cell viability was measured by the MTT reduction assay according to manufacturer's instructions. As positive and negative control for skin irritation, Dulbecco's phosphate-buffered saline (DPBS) and 5\% Sodium Dodecyl Sulfate (SDS) were used, respectively. Moreover, we evaluated the potential skin irritation of cosmetic formulation which contains PMCE using the same reconstructed human skin model. The cosmetic formulation was an oil in water basic cream base with PMCE incorporated (Supplemental Table S3). The parameters measured in vitro were the percentage cell viability using an the MTT Effective Time 50 (ET50) assay after topical application of the products for different exposure times $(2 \mathrm{~h}, 5 \mathrm{~h}$ and $18 \mathrm{~h})$ according to manufacturer's instructions. For negative control, $1.0 \%$ Triton X-100 was used.

Statistical analysis. All the results are presented as mean \pm SEM. One-way ANOVA following by Bonferroni's multiple corrections test was used to detect statistical differences as it has been reported before ${ }^{66-68}$. All data were normally distributed (Kolmogorov-Smirnov test). The level of significance was $\mathrm{p}<0.05$. The statistical analysis was accomplished using SPSS 17.0 (SPSS Inc., Chicago, IL, USA). 
Received: 31 August 2020; Accepted: 23 October 2020

Published online: 05 November 2020

\section{References}

1. Fowler, J. F., Woolery-Lloyd, H., Waldorf, H. \& Saini, R. Innovations in natural ingredients and their use in skin care. J. Drugs Dermatol. 9, S72-S81 (2010) (quiz s82-3).

2. He, C.-N. et al. Phytochemical and biological studies of Paeoniaceae. Chem. Biodivers. 7, 805-838 (2010).

3. Dienaite, L. et al. Isolation of strong antioxidants from paeonia officinalis roots and leaves and evaluation of their bioactivities. Antioxidants 8, 249 (2019).

4. Xu, S.-P. Antiproliferation and apoptosis induction of paeonol in HepG 2 cells. World J. Gastroenterol. 13, 250 (2007).

5. Guo, J.-P. In vitro screening of traditionally used medicinal plants in China against Enteroviruses. World J. Gastroenterol. 12, 4078 (2006).

6. Zheng, Y.-Q., Wei, W., Zhu, L. \& Liu, J.-X. Effects and mechanisms of Paeoniflorin, a bioactive glucoside from paeony root, on adjuvant arthritis in rats. Inflamm. Res. 56, 182-188 (2007).

7. Yang, H. O., Ko, W. K., Kim, J. Y. \& Ro, H. S. Paeoniflorin: An antihyperlipidemic agent from Paeonia lactiflora. Fitoterapia 75, 45-49 (2004).

8. Ning, C., Jiang, Y., Meng, J., Zhou, C. \& Tao, J. Herbaceous peony seed oil: A rich source of unsaturated fatty acids and $\gamma$-tocopherol. Eur. J. Lipid Sci. Technol. 117, 532-542 (2015).

9. Papandreou, V. et al. Volatiles with antimicrobial activity from the roots of Greek Paeonia taxa. J. Ethnopharmacol. 81, 101-104 (2002).

10. Chaita, E. et al. Anti-melanogenic properties of Greek plants. A novel depigmenting agent from Morus alba wood. Molecules 22, 514 (2017).

11. Ali, A. M. A., El-Nour, M. E. M. \& Yagi, S. M. Total phenolic and flavonoid contents and antioxidant activity of ginger (Zingiber officinale Rosc.) rhizome, callus and callus treated with some elicitors. J. Genet. Eng. Biotechnol. 16, 677-682 (2018).

12. Esmaeili, A. K., Taha, R. M., Mohajer, S. \& Banisalam, B. Antioxidant activity and total phenolic and flavonoid content of various solvent extracts from in vivo and in vitro grown Trifolium pratense L. (red clover). Biomed. Res. Int. 2015, 1-11 (2014).

13. Dilkalal, A. \& Umesh, T. G. Evaluation of antioxidant potential and reducing power of callus induced from leaves of a Systasia Gangetica (L.) T. Anderson. Int. J. Pharm. Pharm. Sci. 6, 532-538 (2014).

14. Crouch, S. P. M., Kozlowski, R., Slater, K. J. \& Fletcher, J. The use of ATP bioluminescence as a measure of cell proliferation and cytotoxicity. J. Immunol. Methods 160, 81-88 (1993).

15. Deters, A. M., Schröder, K. R. \& Hensel, A. Kiwi fruit (Actinidia chinensis L.) polysaccharides exert stimulating effects on cell proliferation via enhanced growth factor receptors, energy production, and collagen synthesis of human keratinocytes, fibroblasts, and skin equivalents. J. Cell. Physiol. 202, 717-722 (2005).

16. Tsai, H.-Z., Lin, R.-K. \& Hsieh, T.-S. Drosophila mitochondrial topoisomerase III alpha affects the aging process via maintenance of mitochondrial function and genome integrity. J. Biomed. Sci. 23, 38 (2016).

17. Giampieri, F. et al. Polyphenol-rich strawberry extract protects human dermal fibroblasts against hydrogen peroxide oxidative damage and improves mitochondrial functionality. Molecules 19, 7798-7816 (2014).

18. Sulyok, S., Wankell, M., Alzheimer, C. \& Werner, S. Activin: An important regulator of wound repair, fibrosis, and neuroprotection. Mol. Cell. Endocrinol. 225, 127-132 (2004).

19. Jones, K. L., de Kretser, D. M., Patella, S. \& Phillips, D. J. Activin A and follistatin in systemic inflammation. Mol. Cell. Endocrinol. 225, 119-125 (2004)

20. Eisinger, M., Sadan, S., Silver, I. A. \& Flick, R. B. Growth regulation of skin cells by epidermal cell-derived factors: Implications for wound healing. Proc. Natl. Acad. Sci. 85, 1937-1941 (1988).

21. Mantovani, A. et al. The chemokine system in diverse forms of macrophage activation and polarization. Trends Immunol. 25, 677-686 (2004).

22. Koch, A. et al. Interleukin-8 as a macrophage-derived mediator of angiogenesis. Science (80-). 258, 1798-1801 (1992).

23. Esposito, E. \& Cuzzocrea, S. TNF-alpha as a therapeutic target in inflammatory diseases, ischemia-reperfusion injury and trauma. Curr. Med. Chem. 16, 3152-3167 (2009).

24. Danti, S. et al. Chitin nanofibrils and nanolignin as functional agents in skin regeneration. Int. J. Mol. Sci. 20, 2669 (2019).

25. Coltelli, M.-B. et al. Properties and skin compatibility of films based on poly(lactic acid) (PLA) bionanocomposites incorporating chitin nanofibrils (CN). J. Funct. Biomater. 11, 21 (2020).

26. Azimi, B. et al. Electrosprayed chitin nanofibril/electrospun polyhydroxyalkanoate fiber mesh as functional nonwoven for skin application. J. Funct. Biomater. 11, 62 (2020).

27. Donnarumma, G. et al. $\beta$-defensins: Work in progress. in 59-76 (2015). https://doi.org/10.1007/5584_2015_5016.

28. Fusco, A. et al. Beta-defensin-2 and beta-defensin-3 reduce intestinal damage caused by salmonella typhimurium modulating the expression of cytokines and enhancing the probiotic activity of Enterococcus faecium. J. Immunol. Res. 2017, 1-9 (2017).

29. Johansen, C., Bertelsen, T., Ljungberg, C., Mose, M. \& Iversen, L. Characterization of TNF- $\alpha$ - and IL-17A-mediated synergistic induction of defb4 gene expression in human keratinocytes through ІкBל. J. Invest. Dermatol. 136, 1608-1616 (2016).

30. Adorno-Cruz, V. \& Liu, H. Regulation and functions of integrin a2 in cell adhesion and disease. Genes Dis. 6, 16-24 (2019).

31. Cheli, Y. et al. Transcriptional and epigenetic regulation of the integrin collagen receptor locus ITGA1-PELO-ITGA2. Biochim. Biophys. Acta Gene Struct. Expr. 1769, 546-558 (2007).

32. Li, D. \& Mrsny, R. J. Oncogenic Raf-1 disrupts epithelial tight junctions via downregulation of occludin. J. Cell Biol. 148, 791-800 (2000).

33. Miyagawa, M. et al. Glycosylceramides purified from the japanese traditional non-pathogenic fungus aspergillus and koji increase the expression of genes involved in tight junctions and ceramide delivery in normal human epidermal keratinocytes. Fermentation 5, 43 (2019).

34. Pummi, K. et al. Epidermal tight junctions: ZO-1 and occludin are expressed in mature, developing, and affected skin and in vitro differentiating keratinocytes. J. Invest. Dermatol. 117, 1050-1058 (2001).

35. Jia, Z. et al. Calycosin alleviates allergic contact dermatitis by repairing epithelial tight junctions via down-regulating HIF-1a. J. Cell. Mol. Med. 22, 4507-4521 (2018).

36. Chen, D. et al. Abnormal expression of paxillin correlates with tumor progression and poor survival in patients with gastric cancer. J. Transl. Med. 11, 277 (2013)

37. Turner, C. E. Paxillin and focal adhesion signalling. Nat. Cell Biol. 2, E231-E236 (2000).

38. Sando, G. N. et al. Caveolin expression and localization in human keratinocytes suggest a role in lamellar granule biogenesis. J. Invest. Dermatol. 120, 531-541 (2003).

39. Blouin, C. M. et al. Lipid droplet analysis in caveolin-deficient adipocytes: alterations in surface phospholipid composition and maturation defects. J. Lipid Res. 51, 945-956 (2010).

40. Ovaere, P., Lippens, S., Vandenabeele, P. \& Declercq, W. The emerging roles of serine protease cascades in the epidermis. Trends Biochem. Sci. 34, 453-463 (2009). 
41. De Benedetto, A., Kubo, A. \& Beck, L. A. Skin Barrier Disruption: A Requirement for Allergen Sensitization?. J. Invest. Dermatol. 132, 949-963 (2012).

42. Kishibe, M. Physiological and pathological roles of kallikrein-related peptidases in the epidermis. J. Dermatol. Sci. 95, 50-55 (2019).

43. de Koning, H. D. et al. Expression profile of cornified envelope structural proteins and keratinocyte differentiation-regulating proteins during skin barrier repair. Br. J. Dermatol. 166, 1245-1254 (2012).

44. Anderson, C. M. \& Stahl, A. SLC27 fatty acid transport proteins. Mol. Aspects Med. 34, 516-528 (2013).

45. Khnykin, D., Miner, J. H. \& Jahnsen, F. Role of fatty acid transporters in epidermis. Dermatoendocrinology 3, 53-61 (2011).

46. Lehner, R. \& Quiroga, A. D. Fatty acid handling in mammalian cells. in Biochemistry of Lipids, Lipoproteins and Membranes 149-184 (Elsevier, 2016). https://doi.org/10.1016/B978-0-444-63438-2.00005-5.

47. Amen, N. et al. Differentiation of epidermal keratinocytes is dependent on glucosylceramide:ceramide processing. Hum. Mol. Genet. 22, 4164-4179 (2013).

48. Kolter, T. \& Sandhoff, K. Sphingolipids-Their metabolic pathways and the pathobiochemistry of neurodegenerative diseases. Angew. Chemie Int. Ed. 38, 1532-1568 (1999).

49. Furuse, M. et al. Claudin-based tight junctions are crucial for the mammalian epidermal barrier. J. Cell Biol. 156, 1099-1111 (2002).

50. Radner, F. P. W. et al. Growth retardation, impaired triacylglycerol catabolism, hepatic steatosis, and lethal skin barrier defect in mice lacking comparative gene identification-58 (CGI-58). J. Biol. Chem. 285, 7300-7311 (2010).

51. Scharschmidt, T. C. et al. Filaggrin deficiency confers a paracellular barrier abnormality that reduces inflammatory thresholds to irritants and haptens. J. Allergy Clin. Immunol. 124, 496-506.e6 (2009).

52. Macheleidt, O., Sandhoff, K. \& Kaiser, H. W. Deficiency of epidermal protein-bound $\omega$-hydroxyceramides in atopic dermatitis. J. Invest. Dermatol. 119, 166-173 (2002).

53. Li, Y. et al. Golmaenone, a new diketopiperazine alkaloid from the marine-derived fungus Aspergillus sp.. Chem. Pharm. Bull. (Tokyo). https://doi.org/10.1248/cpb.52.375 (2004).

54. Hong, K.-K., Cho, H.-R., Ju, W.-C., Cho, Y. \& Kim, N.-I. A study on altered expression of serine palmitoyltransferase and ceramidase in psoriatic skin lesion. J. Korean Med. Sci. 22, 862 (2007).

55. Hannun, Y. A. \& Obeid, L. M. Sphingolipids and their metabolism in physiology and disease. Nat. Rev. Mol. Cell Biol. 19, 175-191 (2018).

56. Holleran, W. M., Takagi, Y. \& Uchida, Y. Epidermal sphingolipids: Metabolism, function, and roles in skin disorders. FEBS Lett. 580, 5456-5466 (2006).

57. Wennekes, T. et al. Glycosphingolipids-nature, function, and pharmacological modulation. Angew. Chemie Int. Ed. 48, 8848-8869 (2009).

58. van Smeden, J., Janssens, M., Gooris, G. S. \& Bouwstra, J. A. The important role of stratum corneum lipids for the cutaneous barrier function. Biochim. Biophys. Acta Mol. Cell Biol. Lipids 1841, 295-313 (2014).

59. Ishikawa, J. et al. Changes in the ceramide profile of atopic dermatitis patients. J. Invest. Dermatol. 130, 2511-2514 (2010).

60. Faller, C., Bracher, M., Dami, N. \& Roguet, R. Predictive ability of reconstructed human epidermis equivalents for the assessment of skin irritation of cosmetics. Toxicol. Vitr. 16, 557-572 (2002).

61. Cannon, C. L., Neal, P. J., Southee, J. A., Kubilus, J. \& Klausner, M. New epidermal model for dermal irritancy testing. Toxicol. Vitr. 8, 889-891 (1994).

62. Murashige, Skoog. A revised medium for rapid growth and bioassays with tobacco tissue cultures. Physiol. Plant. 15, 473-492 (1962).

63. Chakraborthy, G. S. \& Ghorpade, P. M. Free radical scavenging activity of Abutilon indicum (Linn) sweet stem extracts. Int. J. ChemTech Res. 2, 526-531 (2010).

64. Brand-Williams, W., Cuvelier, M. E. \& Berset, C. Use of a free radical method to evaluate antioxidant activity. Leb. Technol. 30, 25-30 (1995).

65. Molyneux. The use of the stable free radical diphenylpicrylhydrazyl (DPPH) for estimating antioxidant activity. Songklanakarin J. Sci Technol. 26, 211-219 (2003).

66. Letsiou, S. et al. In vitro protective effects of marine-derived Aspergillus puulaauensis TM124-S4 extract on $\mathrm{H}_{2} \mathrm{O}_{2}$-stressed primary human fibroblasts. Toxicol. Vitr. 66, 104869 (2020).

67. Letsiou, S., Kapazoglou, A. \& Tsaftaris, A. Transcriptional and epigenetic effects of Vitis vinifera L. leaf extract on UV-stressed human dermal fibroblasts. Mol. Biol. Rep. 47, 5763-5772 (2020).

68. Letsiou, S. et al. Skin protective effects of Nannochloropsis gaditana extract on $\mathrm{H}_{2} \mathrm{O}_{2}$-stressed human dermal fibroblasts. Front. Mar. Sci. 4, (2017).

69. Ramakers, C., Ruijter, J. M., Deprez, R. H. L. \& Moorman, A. F. Assumption-free analysis of quantitative real-time polymerase chain reaction (PCR) data. Neurosci. Lett. 339, 62-66 (2003).

70. Löwenau, L. J. et al. Increased permeability of reconstructed human epidermis from UVB-irradiated keratinocytes. Eur. J. Pharm. Biopharm. 116, 149-154 (2017).

\section{Acknowledgements}

This study was made possible thanks to financial support provided by APIVITA SA.

\section{Author contributions}

S.L. conceived, planned, and oversaw the experiments. A.B. carried out the experiments on the RT-qPCR analysis. A.H. and J.R. initiated the callus cell line and carried out experiments on the antioxidant assay and on HPLC analysis. S.L. analyzed and integrated the datasets and drafted the manuscript. All authors critically read and contributed to improving the MS.

\section{Competing interests}

The authors declare no competing interests.

\section{Additional information}

Supplementary information is available for this paper at https://doi.org/10.1038/s41598-020-76169-0.

Correspondence and requests for materials should be addressed to S.L.

Reprints and permissions information is available at www.nature.com/reprints.

Publisher's note Springer Nature remains neutral with regard to jurisdictional claims in published maps and institutional affiliations. 
(c) (i) Open Access This article is licensed under a Creative Commons Attribution 4.0 International cc) License, which permits use, sharing, adaptation, distribution and reproduction in any medium or format, as long as you give appropriate credit to the original author(s) and the source, provide a link to the Creative Commons licence, and indicate if changes were made. The images or other third party material in this article are included in the article's Creative Commons licence, unless indicated otherwise in a credit line to the material. If material is not included in the article's Creative Commons licence and your intended use is not permitted by statutory regulation or exceeds the permitted use, you will need to obtain permission directly from the copyright holder. To view a copy of this licence, visit http://creativecommons.org/licenses/by/4.0/.

(C) The Author(s) 2020 